\title{
The Correlation of Brand Equity and Crisis: A Review and Directions for Future Research
}

\author{
Liuying He, Yaxuan Ran \\ Management College, Jinan University, Guangzhou, China \\ Email: heliuying@163.com
}

Received 23 February 2015; accepted 15 March 2015; published 18 March 2015

Copyright (C) 2015 by authors and Scientific Research Publishing Inc.

This work is licensed under the Creative Commons Attribution International License (CC BY). http://creativecommons.org/licenses/by/4.0/

c) (i) Open Access

\begin{abstract}
The relations between brand equity and crisis draw the attentions of theorists and practitioners. Previous researches were unidirectional, which suggested that brand equity has an impact on crisis, or crisis influence brand equity. However, the two-way effects between crisis and brand equity are still unknown. The purpose of this paper is to review the findings like the factors that crisis affect brand equity, as well as the process of how brand equity adjusts severity or evaluation of crisis. The researches on the bidirectional mechanism behind the relationship of brand equity and crisis are insufficient, which will be the important directions in the future.
\end{abstract}

\section{Keywords}

Crisis, Brand Equity, Two-Way Effect, Response to the Crisis

\section{Introduction}

Brand equity, which is the most important intangible assets [1], would inevitably meet crisis no matter how strong it is. As the consumer's cognition and the involvement of the media, crisis management has become a significant part in daily administrations [2]. Laurence Barton presented that the crisis is an uncertain event which will cause potential negative impact. The occurrence of it may lead to huge damage to its organization, staff, product, property and reputation [3]. Since crisis is so frequent and brand equity is so crucial to enterprise, some theoretical studies have been studying their relationship.

On the one hand, the crisis influences brand equity. Zheng F's studies show that the crisis might damage brand equity through influencing perceived quality, purchasing intention, brand attitude [4]. Thus, most theoretical studies about crisis’s influence to enterprises would set brand equity as a dependent variable. 
On the other hand, brand equity influence crisis. Lin thinks that the crisis outbreaks will bring lots of new challenges to the enterprise marketing, whether the traditional theory can be also used to deal with the crisis has not been verified effectively, and entrepreneurs have to recognize and grasp the functions of all kinds of marketing factors [5]. Keller thinks brand equity, as a vital marketing factor, can make a positive effect in many ways, such as enhancing consumers' loyalty, reducing consumers' elastic reaction, weakening the influence of competitors' marketing campaign [6]. Therefore, how brand equity affect crisis is still questionable.

According to the above researches, crisis influence brand equity and brand equity also influence brand equity. Scholars explore the interaction effect between brand equity and crisis in the two ways without combination. In this paper, We overview the remaining theories and conclusions, investigate the interaction effect in both angels, and make the future research direction about their relationship to expect to definite the interaction mechanism between brand equity and crisis.

\section{The Impact of Crisis to Brand Equity}

Focus on the characteristic of crisis, most studies about crisis mainly are public crisis, product harm crisis [7] [8], corporate crisis and brand crisis [9] [10], all kinds of these the crisis have abruptness, urgency and destructiveness.

Brand equity is the important carrier of enterprise credit and enterprise assets, the crisis happened will inevitably affect it. After the happening of the crisis, enterprises have to response to it, but different response strategies mean different remediation effect and different influence to brand equity. Furthermore, crisis mainly damage consumers' confidence, and consumers' own features would also adjust crisis' impact on brand equity. Thus, on the crisis impact on brand equity, theoretical studies can be divided into three parts: impact of crisis relative elements on brand equity, impact of coping strategies to crisis on brand equity, and impact of consumer feature adjustment to crisis on brand equity.

\subsection{Impact of Crisis Relative Elements on Brand Equity}

Brand equity has three definitions from three perspectives: consumer-based brand equity [6], employee-based brand equity [11] and financial perspective-based brand equity. In marketing field, consumer-based brand equity, which brand equity means consumer-based brand equity, draws a lot of attention as consumers' perception is the key point in marketing management.

Consumers' perspective and behavioral intention is sensitive; some unexpected and serious external events with other factors would affect it [12]. It is generally agreed by the academy that crisis weaken the brand equity. Dawar and Lei think that both correlation between crisis itself and brand association and crisis severity have an impact on consumers' evaluation to the brand and then influence the brand equity. In other words, the more relative the crisis is with brand association, the more harm crisis will do to brand equity. And consumers' perspective to the crisis severity is incomplete intermediary variable to the impact of crisis correlation on brand equity. The higher extent of the perspective, the larger damage it will do to brand equity.

Based on the conclusion that crisis weakens brand equity, it is generally agreed by the academics that the original cause of the influence is the transgression of consumers' expectation. So, as long as the expectation of the consumers is not broken, the influence of the crisis to brand equity is little. It is Dawar and Pillutla find that whatever measures the enterprises take, once consumers keep a high confidence to the company's brand, loss of the brand equity would be rather less. Wu [13], a Chinese scholar, made the similar conclusion in 2008.

\subsection{Impact of Coping Strategies to Crisis on Brand Equity}

Enterprises' reaction is the key element judging consumers' faith to the enterprise and consumers' faith is the main factor in obtaining enterprises' brand equity (Aaker, 1991). When it comes to the classification of coping strategies to crisis, numerous scholars like Allen and Caillouet, Benoit and Coombs [14] put forward their opinions from different perspectives, including denying(insist that none crisis happened and deny the accusation to enterprises' crisis), keeping distance (accept the crisis but try to reduce the contact between the organization and the crisis), pandering (seek public support actively), feeling shamed (attempt to acquire forgiveness) and bearing (describe itself as the victim of the crisis). Though numerous scholars explore the impact of coping strategies to crisis on brand equity, they cannot make a standard idea on which coping strategies is the best. 
Some scholars insist that apology voluntarily and compromise is the best response. Dawar and Pillutla make an explanation about coping style to crisis influencing brand equity that crisis with its coping methods is a signaling mechanism, which will effect component factors like brand faith and brand attitude, from the angel of information economics, based on the study about product harm crisis. Through examining the theoretical environment based on expectation-evidence framework, Dawar \& Pillutla suppose the effective remedial measure to protect brand equity in danger and convey the favorable signal is take valid coping strategy and take the responsibility actively and precisely, rather than deny or make an ambiguous attitude.

Some scholars consider types of crisis decide relevant coping strategies, but their classification standards are not consistent. On studying the impact of brand crisis' remediation strategy on brand equity, Dutta and Pullig [15] divide brand crisis into performance-related brand crisis and value-related brand crisis. They believe that reducing the attack is the best reaction for the performance-related brand crisis and amending and cutting down attacks are better than denying for the value-related brand crisis. Fang et al. separate product harm crisis into "defensible" and "indefensible", in their study, according to Smith [16]'s classification standard whether the product defects and damage violate relative laws and regulations or safety standards. The study finally comes to a conclusion that for defensible product harm crisis, the best strategy to protect product property is arguing, and then attacking, keeping silent and last compromising. On the contrary, for indefensible crisis, compromising is the wisest strategy [4].

\subsection{Impact of Consumer Feature Adjustment to Crisis on Brand Equity}

In crisis, various purchasing types of consumers and demographics affect the brand equity. For buying behavior, there are different difficulties for enterprises to preserve the brand reputation and brand loyalty with four kinds of consumers' behavior who reduce uncontrollable buying, complex buying, diverse buying or habitual buying. $\mathrm{Wu}$, in his study about individual difference's influence to brand equity, found heavy consumers (with high buying frequency) will keep their brand attitude, quality perspective, purchasing intention and brand desirability in a larger extent, comparing with light consumer (with low buying frequency). If reducing consumers' anxiety, Consumer-based brand equity will loss less. At the same time, differences among consumers' characteristic also have an influence on attribution. According to Laufer's study, female consumers find themselves easier to be hurt in the negative brand publicity and their blame to the exposing enterprise is more than male consumers'. And found in his study about gender and age adjusting brand loyalty, an dimension of brand equity, that female consumers' perspective danger is higher than male consumers, and their loyalty drop more dramatically than male consumers; the larger the age is, the higher extent the perspective danger is in and the more seriously the loyalty will drop. In addition, similar conclusions have been drawn in Buger and Schaie's, Hertzog and Heekhausen's and Schulz's studies. It is a good verification for social psychology theoretical analysis.

\section{The Effects of Brand Equity to Crisis}

Brand equity is a multi-dimensional concept, which includes brand desiring, Brand trust, brand loyalty and commitment, brand image and reputation and etc. From concrete objects of study, studies of brand equity's influence to crisis can be separated into two types. One is to directly brand assets as the object; the other is an object with a dimension of brand assets. Scholars draw different conclusions on whichever objects.

\subsection{Brand Equity Weaken the Influence of Crisis}

It is showed by Siomkos et al. [17], Ahluwalia [18] as well as Sloot et al. [19] studies that brand equity can weaken the influence of negative marketing events.

Taking the brand equity as object, Sloot $e t$ al. find high brand equity consumers show greater loyalty to the high-brand product than low brand equity consumers, when crisis occurs when crisis occurs. However, this function would be affected by product natures, which means consumers show higher loyalty to functional products in contrast with extravagant products, in the situation of same high brand equity.

Both Ahluwalia et al. taking a dimension of brand equity as target, they studied brand equity's influence to crisis. Targeting the commitment as a dimension of brand equity, Ahluwalia et al. [20] find that a crisis burst out show a negative information effect to the consumers with a low brand commitment level, but not available to consumers with high brand commitment. For consumers with low commitment, the mental mechanism generating 
the effect is the judgment of the information diagnosability. For the other consumers with high commitment, their mental mechanism is the explanation of the negative information. Another study taking the reputation dimension of brand equity done by Siomkos et al. found that consumers Perceive lower risk and stronger purchase intention to a brand with higher reputation than one with lower reputation, when facing same negative marketing events and enterprise response.

\subsection{Brand Equity Aggravate the Effect of Crisis}

The Rhee et al. [21] and the Dean [22] find the negative influence of brand equity to enterprises when crisis occurs. The focus of this research is the reputation of enterprises' brand equity. The Dean's research suggests two conclusions, one is that when enterprises take out unreasonable response to deal with crisis, the attitude of consumers towards those enterprises with high reputation will go worse while towards to the lower will improve, another is that even when the famous enterprises make a reasonable response to crisis, they still have to bear the negative influence if consumers believe they should be responsible for the crisis. That means no matter whether the enterprise is responsible for the crisis, the enterprises with high reputation endure worse effect.

Besides, the study in Rhee et al. on automotive industry has reached the same conclusion by using a different theory. Rhee et al. use the expectation-disconfirmation theory as the framework in the research. According to this theory, consumers had an expectation on a product or service based on some clues. When their expectation cannot be met, they will be disappointed. The research by Rhee et al. has pointed out that the brand equity will increase the expectations of consumers to the enterprises, as well as the brand. Generally, consumers believe that the enterprise with high brand equity will provide the products and service that are of high quality and low risk. By contrast, the enterprises with lower brand equity always get lower expectation from consumers. So, the enterprises with higher brand equity will have a greater degree of the disappointment from consumers. This also means the brand equity will aggravate the effect of crisis.

\subsection{Double-Edged Sword Role of Brand Assets}

Recently, the double-edged sword role in the research of brand assets mainly has three aspects. Firstly, the dimension of brand equity in some aspects can weaken the influence on the crisis while strengthen the influence of the crisis in some other dimension, Secondly, the brand assets in some time can weaken the crisis while strengthen the influence of the crisis in some other time, thirdly, the brand assets from a certain perspective can weaken the crisis, the influence of from another perspective it is strengthen the influence of the crisis.

The influence of the double-edged sword role of brand assets in different dimensions: a research which studied in commitment dimension of brand equity by Mattila found that ,when the crisis occurs, high commitment consumers' attitude toward the brand will be fell quickly, while lower commitment consumers tend to forgive the brand, the brand assets on commitment dimensions will strengthen the influence of the crisis, another dimension of brand equity, consumer loyalty as the study found that the influence of brand equity will weaken the crisis.

The influence of double-edged sword role in different time: the research by Roehm and Brady [23] indicates that, if let the consumer immediately after the crisis to evaluate brand, higher brand equity brand in crisis when the extent of the assets fell below, that means brand equity can weaken the crisis, If the delay for a period of time let consumers to evaluate the brand, the brand assets is higher, the satisfaction of consumers to the brand greater, that means brand equity will aggravate the crisis. In short, the brand assets can weaken its influence in a crisis occurs, after a period of time will strengthen the influence of the crisis.

The influence of double-edged sword role in different perspectives: Brady, Cronin, Fox and Roehm measured brand equity in the view of the two double-edged sword roles by the size of overall satisfaction decrease. Brady, Cronin, Fox and Roehm's study find that whether the enterprise deal with negative marketing events or not, high brand asset consumers' satisfaction and purchase intention are still higher than the low brand assets after the incident. However, high brand assets consumers' satisfaction and purchase intention decline a greater degree after the negative marketing events.

\section{Prospects for Future Research Directions}

Although there had been lots of researches about crisis and brand equity, these two topics are still a hotspot. For 


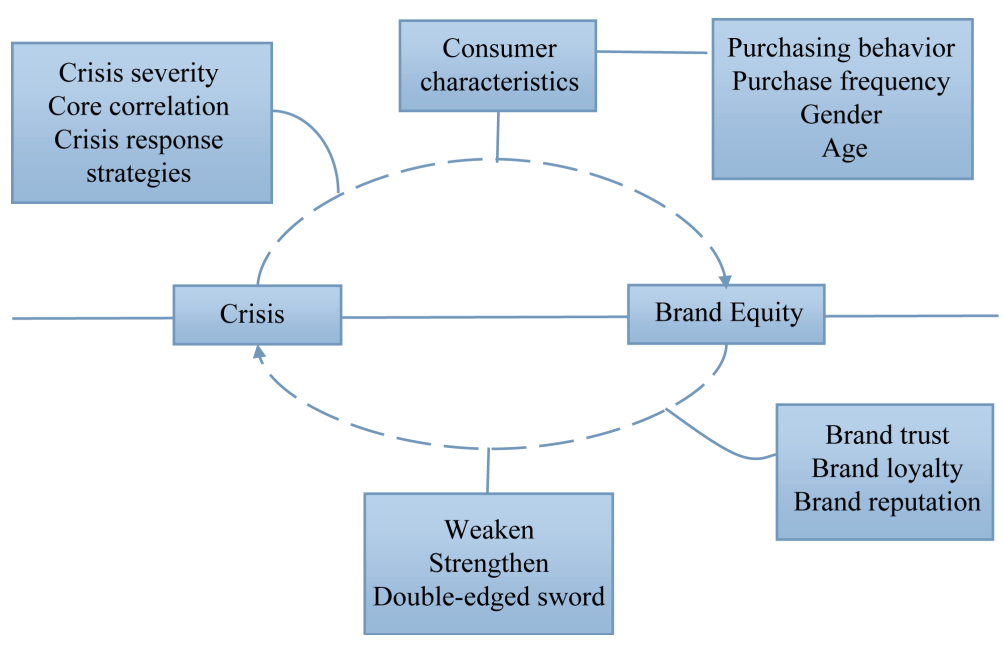

Figure 1. Mutual effects of the crisis and brand equity.

the reason that, the crisis breaks out frequently in reality while the researches about the crisis in theory are narrow, and whether from the point of marketing elements or brand ability, brand equity is an emphasis of the study. Brand equity has an influence on the result of crisis, such as brand attitude and consumer repurchase intention [24]. In addition, crisis itself will also influence the brand equity; meanwhile coping strategies of the crisis will affect the brand equity. According to the above literature review, we propose a new framework including the mutual influence of the crisis and brand equity.

Among these (Figure 1), the severity and core correlation of the crisis will affect brand equity or its dimensions when a crisis occurs and crisis response strategies after the crisis will also affect brand equity. Therefore, enterprises can choose the optimal strategy in crisis situations depending on the impact of these policies. In addition, some characteristics factors of consumers, such as purchasing behavior, purchase frequency, gender and age, will regulate the impact of crisis on brand equity. In turn, brand equity itself or its dimensions, such as brand trust, brand loyalty and brand reputation, will affect crisis. They draw three different conclusions including strengthening, weakening, or strengthening in some respects and weakening in other respects. These conclusions have diametrically opposite results, which is due to the following aspects, first, inconsistency from the diversity of variable choosing in the brand equity empirical research. Some researches choose brand expectation and some others choose purchase intention; second, variety of moderating variables' choosing, including product property, time and environment of evaluation's disturbance to consumers' attention, gravity of the even, promptness to consumers, and substitutability among brands; third, in studying brand equity 's function in crisis, there are multiple situations, complicated conditions and numerous theoretical basis so that conclusions of research come to different levels.

Based on the content mentioned above, there are two points. Firstly, an interactional dynamic process exists between crisis and brand equity while existing studies mainly focus on brand equity's one-way effect to crisis, ignoring the impact crisis back to the brand equity.

Secondly, brand equity is consumers' cognition to the brands, which change with people's mind, and past research haven't explored consumers' mental mechanism. Thus, dynamic influence of crisis and brand equity can take peoples' mental mechanism into account so that we can explain the crisis from a dynamic and psychological angle as well as put forward new suggestions to crisis response and precaution.

\section{References}

[1] Aaker, D.A. (1990) Managing Brand Equity. Macmillan, New York.

[2] Brady, M., Cronin, J., Fox, G. and Roehm, M.L. (2008) Strategies to Offset Performance Failure: the Role of Brand Equity. Journal of Retailing, 84, 151-164. http://dx.doi.org/10.1016/j.jretai.2008.04.002

[3] Barton, L. (1994) Crisis Management Planning: The Ultimate Weapon in Protecting Competitive Advantage. Competitive Intelligence Review, 5, 31-35. http://dx.doi.org/10.1002/cir.3880050209

[4] Fang, Z. and Yang, Y. (2011) Research on the Influence of Protecting Brand Equity in the Event of Defensible Product 
Harm Crisis by Appropriate Remedial Response: Moderating and Mediating Effects. Nankai Management Review, 14, 69-79.

[5] Lin, Z., Zhao, X., Ismail, K.M. and Carley, K.M. (2006) Organizational Design and Restructuring in Response to Crises: Lessons from Computation Modeling and Real-World Cases. Organization Science, 17, 598-618. http://dx.doi.org/10.1287/orsc.1060.0210

[6] Keller, L.K. (1993) Conceptualizing, Measuring, and Managing Consumer-based Brand Equity. Journal of Marketing, 57, 1-22. http://dx.doi.org/10.2307/1252054

[7] Dawar, N. and Pillutla, M. (2000) Impact of Product-Harm Crisis on Brand Equity: the Moderating Role of Consumer Expectations. Journal of Marketing Research, 37, 215-226. http://dx.doi.org/10.1509/jmkr.37.2.215.18729

[8] Fang, Z. and Jiang, M.H. (2010) Product Harm Crisis Response Strategy Research on the Influence of Brand EquityAdjustment of Corporate Reputation and the Crisis Type. Management of the World, 12, 105-118.

[9] Dawar, N. and Lei, J. (2009) Brand Crises: The Roles of Brand Familiarity and Crisis Relevance in Determining the Impact on Brand Evaluations. Journal of Business Research, 62, 509-516. http://dx.doi.org/10.1016/j.jbusres.2008.02.001

[10] Wu, H.Y. (2011) Brand Crisis Management-Based on the Research of Brand Relationship Perspective. Jinan University Press, Guangzhou, 34-36.

[11] King, C. and Grace, D. (2010) Building and Measuring Employee-Based Brand Equity. Journal of Marketing, $44,147$.

[12] Dawar, N. and Pillutla, M.M. (2000) Impact of Product-Harm Crisis on Brand Equity: The Moderating Role of Consumer Expectations. Journal of Marketing Research, 37, 215-226. http://dx.doi.org/10.1509/jmkr.37.2.215.18729

[13] Wu, X.M. (2008) Consumer Individual Differences Affect Brand Equity Research. China's Circulation Economy, 10, 55-5.

[14] Coombs, W.T. (1999) Information and Compassion in Crisis Response: A Test of Their Effects. Journal of Public Relations Research, 11, 125-142. http://dx.doi.org/10.1207/s1532754xjprr1102_02

[15] Dutta, S. and Pullig, C. (2011) Effectiveness of Corporate Responses to Brand Crises: The Role of Crisis Type and Response Strategies. Journal of Business Research, 64, 1281-1287. http://dx.doi.org/10.1016/j.jbusres.2011.01.013

[16] Smith, L. (2003) Media Strategies in Product Liability Crises. Of Counsel, 22, 6-11.

[17] Siomkos, G.J. and Kurzbard, G. (1994) The Hidden Crisis in Product-Harm Crisis Management. European Journal of Marketing, 28, 30-41. http://dx.doi.org/10.1108/03090569410055265

[18] Ahluwalia, R., Burnkrant, R.E. and Unnava, H.R. (2000) Consumer Response to Negative Publicity: The Moderating Role of Commitment. Journal of Marketing Research, 37, 203-214. http://dx.doi.org/10.1509/jmkr.37.2.203.18734

[19] Sloot, L.M., Verhoef, P.C. and Franses, P. (2005) The Impact of Brand Equity and The Hedonic Level of Products on Consumer Stock-Out Reactions. Journal of Retailing, 81, 15-34. http://dx.doi.org/10.1016/j.jretai.2005.01.001

[20] Raju, S. and Unnava, R. (2006) The Role of Arousal in Commitment: An Explanation for the Number of Counterarguments. Journal of Consumer Research, 33, 173-178. http://dx.doi.org/10.1086/506298

[21] Rhee, M. and Haunschild, P.R. (2006) The Liability of Good Reputation: A Study of Product Recalls in the US Automobile Industry. Organization Science, 17, 101-117. http://dx.doi.org/10.1287/orsc.1050.0175

[22] Dean, D.H. (2004) Consumer Reaction to Negative Publicity: Effect of Corporate Reputation, Response, and Responsibility for a Crisis Event. International Journal of Business Communication, 41, 192-211. http://dx.doi.org/10.1177/0021943603261748

[23] Roehm, M. and Brady, M. (2007) Consumer Response to Performance Failures by High-Equity Brands. Journal of Consumer Research, 34, 537-545. http://dx.doi.org/10.1086/520075

[24] Huang, J. and Xiong, W. (2009) The Effect of Input by the Brand that Made Mistakes on Consumers' Willing of Relationship-Rebuilding. China Soft Science, 6, 119-127. 